cntirely within its rights to emphasize the intellectual difficulty of balancing benefits and side-effects. The panel is also right to emphasize that many existing instruments of government-the regulatory agencies such as the Food and Drug Administration in the United States-serve to constrain the natural tendencies of technology to respond to the influences of the free market. The problem, however, is to devise ways of restraining the new technologies, for which regulations have not been devised, and the panel goes on to shake its head in sorrow over many of the troubles or near troubles of the past few years - the spread of DDT, the air pollution caused by automobiles and even the influence of television on the pattern of society. It is clever of the panel to have insisted that the real difficulty in predicting the effect of an innovation is not so much qualitative as quantitative.

Here and there throughout the report are references to the way in which innovations have brought untoward effects. The report, for example, asks more in sorrow than in anger why the introduction of organo-chlorine pesticides a quarter of a century ago was not more gradual and deliberate, with an ettempt to foresee that these materials would accumulate in some parts of some food chains. The panel goes on to say that there is a suspicion-it emphasizes that it can be no more-that accumulated pesticides in human livers may already be causing subtle kinds of damage. The moral which it draws is that there should have been some agency responsible for examining the likelihood that innovations like these would have harmful side-effects, and it is a short step from there to the recommendation that the Office of Science and Technology and the National Science Foundation should both have grafted to them departments for making forward assessments of the consequences of technology, the former in an executive role and the latter as a grant-giving body.

The trouble, of course, is that nobody will be confident that such organizations, however enlightened they may be, can effectively avoid any but the more obvious dangers. There is even a possibility that institutions like the Office of Science and Technology, concerned as they must be with the efficient implementation of government policy, will frequently find themselves internally in conflict in assessments of the consequences of innovation. In a curious way the Panel on Technology Assessment, having accurately proclaimed that the interesting problems are political in character, then goes on to advocate a scheme for curing political conflict in what would be a quasi-judicial arm of the technical civil service. The chances are that such a system would provide cither the wrong advice or none at all.

What, then, should be done? There is a need for much more research on some aspects of problems of technological innovation, as, for example, in the study of the long-term effects of the pill or the consequences of factory farming. The Panel of the Academy of Sciences is within its rights in asking that some body like the National Science Foundation should be more free than in the past to spend money on projects like these. Within the technical community, there is a need for a much more outspoken discussion of the pros and cons of potential developments, and it is laughable that technical opinions should often be as one-sided as those of out and out propagandists. This is why, as in the conflict between technical opinions about the damage caused by sonic booms, itself the product of technical uncertainty, nobody can accurately know just who to trust. In the long run, however, the function of technical opinion is not so much to arbitrate botween opposing views as to inform and even to stimulate discussion in a wider circle. The great merit of the report by the Panel on Technology Assessment is that it demonstrates as convincingly as the American Constitution itself that matters which concern the people at large can only properly be decided by the people.

\section{PARTY CONFERENCES}

\section{European and Party Unity}

Brighton is now poised between party conferences. The Liberal conference which took place last week afforded the now familiar sight of the Young Liberals adopting a more radical and militant approach than that of the parent body, and being subsequently chastised for it. But the motion which had the greatest bearing on science and technology, on European unity, was largely their work.

This motion commits the Liberal Party to press not only for entry into the EEC but also for a "United States of Europe" with common economic, technological and foreign policies. The Liberals see this as the only effective way to combat the increasing American dominance of European technology and consumer markets, but perhaps the most surprising aspect of the motion is that it calls for a common defence policy based on conventional and not on nuclear weapons. This would require that both Britain and France should relinquish their nuclear armouries, and renders the Liberal policy on general nuclear disarmament rather unclear. The motion was carried by an overwhelming majority, and this makes the Liberal Party the foremost advocate of joining the Common Market among the political parties.

On education, the Liberals carried a motion calling for sweeping changes in the whole spectrum from primary to higher education (see Nature, 223, 1088; 1969). The principal changes called for were the provision of nursery schools for at least one third of the age group; raising the age of transfer to secondary education to twelve or thirteen and that from secondary to tertiary education to seventeen; the provision of two or three year colleges for up to one third of that age group, for pre-university or pre-vocational training; the abolition of GCE O-level and the acceptance of a single national examination as a test of fitness for entry to university. The debate on the motion centred more on the methods for carrying out these plans than on the principles embodied in it.

Apart from these two motions, there was little in the conference bearing on science and technology. Mr Eric Lubbock, the Liberal Chief Whip in the House 
of Commons, said that these issues are unfortunately not likely to catch the imagination of the public, but that he hoped to submit a short motion to the next conference which would be based on recommendations from a recent meeting on the proper use of scientific manpower. But, like the Liberals, delegates to the Labour Party Conference will not find themselves overburdened with science and technology issues. The major debates will almost certainly be concerncd with economic policy and trade union legislation, but the motions on education and the National Health Service will affect some areas of science indirectly.

In contrast with the Liboral motion on education, those submitted to the Labour conference are surprisingly dull and are mainly concerned with speeding up the process of changing to comprehensive education. The Socialist Education Association is calling for a single public examination at sixteen, the abolition of all private education and the mandatory provision of nursery education by local education authorities. Other motions call for a review of the current concept of examinations as a means of assessment and four term years in higher and further education. Prescrip. tion charges will doubtless come under attack if a composite motion on the health service is debated, but more sweeping changes are likely to be proposed in motions calling for the nationalization of the drug industry.

\section{TRADES UNIONS}

\section{Science and the TUC}

Predictably, the Trades Union Congress held in Portsmouth earlier this month was dominated by debates on government policy in the industrial sphere, and little time was spent on matters having a direct bearing on science and technology. But many matters discussed could influence the conduct of research and development indirectly. Thus there was a call for a policy for mergers laying down a "code of action" for industrial takeovers; acceptance of that part of the report of the General Council of the IUC concerned with Britain's technological progress, drug industry profits and the National Health Scrvice, and the European Economic Community.

The TUC does concern itself quite extensively with matters bearing on science and technology, however; the report of the General Council to Congress included paragraphs on Britain's technological progress, European technological cooperation, pressure vessels, carbon fibres and the Social Sciences Research Council. The fact that these issues were not debated reflects popular indifference to science policy issues. But Mrs Muriel Turner of the Association of Scientific, Technological and Managerial Staffs drew attention during the congress to a paragraph in the report which was concerned with women in scientific careers. She pointed out that the number receiving scientific or technical training was negligible and urged that a campaign be started to help recruit more women into science. And this, after all, was the TUC which came out in favour of equal pay for men and women.

$\mathrm{Mr}$ Clive Jenkins, general secretary of ASSETT, proposing an amendment which called for the abandonment of Britain's efforts to join the EEC, did not concern himself with the paragraph in the General
Council's report on European Technological Cooperation but voiced several doubts on agricultural grounds about the advisability of entering the EEC. He stated that the Treasury would have to find an extra $£ 600$ million a year, and that the majority of people in Britain were not in any case in favour of entering the EEC on existing terms. Before the amendment was put to a vote which would have resulted in ignominious defeat, Mr Jenkins withdrew it.

In a motion calling for the abolition of Health Service charges, Mr Bob Edwards of the chemical workers gave as the main reason for the financial plight of the NHS the vast profits being made by the drug industry. He suggested that if the Government carried out one recommendation of the Sainsbury Committee-the abolition of branded drugs-this would recover enough money from drug profits to pay for a free health service. This motion, which was passed overwhelmingly, also called for a new system for controlling hospitals and the health service, based on trade union, professional and local government representation.

\section{AIRPORTS \\ living without Stansted}

THE British Airports Authority is still smarting from the decision of the British Government in February 1968 to throw the question of where to build a third London airport on the shoulders of a commission under Mr Justice Roskill. In its annual report for the year ending in March, the authority is at great pains to point out how the postponement of the plan for a third airport at Stansted has interfered with its forward planning. Close readers of the report may well, however, be disappointed by the authority's scant acknowledgment that the opponents of the plan to build at Stansted may have had a case. At one point, the authority suggests that this change of plan was "a result of
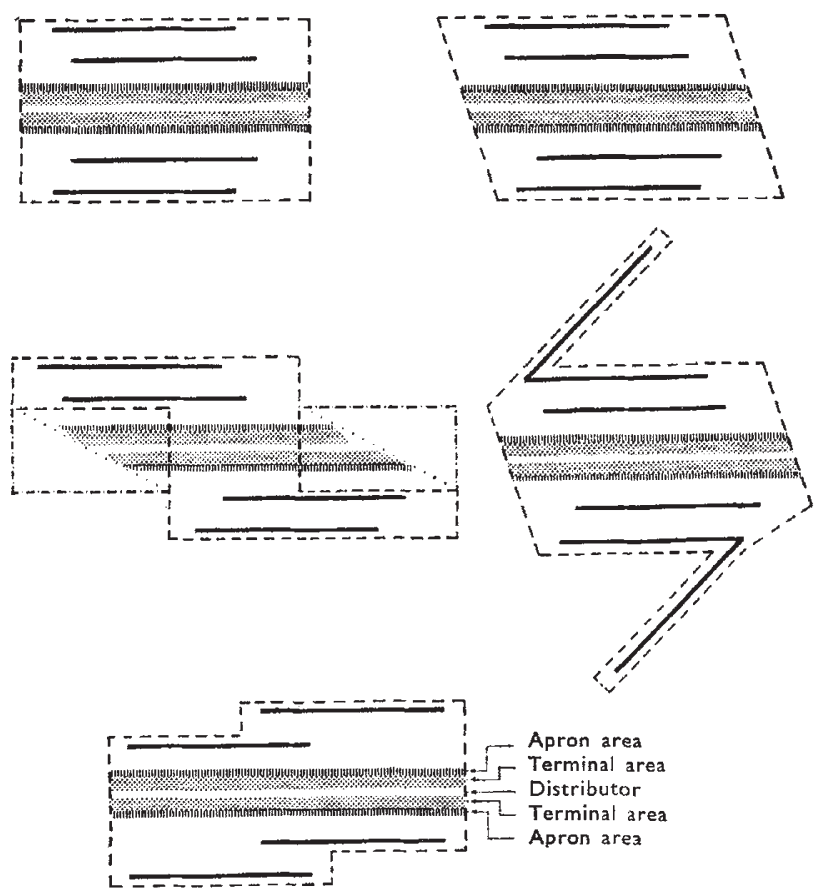

Possible alternatives for a multi-runway airport. Runway length, 14,000 feet. 